\title{
A foliar rating system for comparing the resistance of banana cultivars grown as tissue-cultured plantlets in the laboratory to Fusarium wilt
}

\author{
N. Nasir ${ }^{\mathrm{A}, \mathrm{D}}$, P. A. Pittaway ${ }^{\mathrm{B}, \mathrm{E}}$, K. G. Pegg ${ }^{\mathrm{C}}$ and A. T. Lisle $^{\mathrm{A}}$

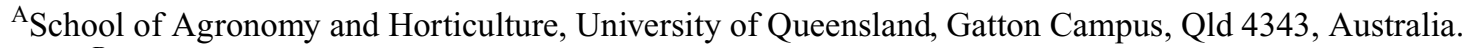 \\ ${ }^{\mathrm{B}}$ Chrysalis Landscape Consultants, 31 Douglas McInnes Drive, Laidley, Qld 4341, Australia. \\ ${ }^{\mathrm{C}}$ Queensland Horticulture Institute, Queensland Department of Primary Industries, Meiers Road, Indooroopilly, \\ Qld 4068, Australia. \\ ${ }^{\mathrm{D} C u r r e n t}$ address: Solok Research Institute for Fruits, Department of Agriculture, PO Box 5, West Sumatra, \\ Indonesia. \\ ${ }^{\mathrm{E}}$ Corresponding author; email: grubb@hypermax.net.au
}

\begin{abstract}
A foliar rating system was developed to assess the progress of Fusarium wilt (Panama disease) caused by Fusarium oxysporum f. sp. cubense in seven banana cultivars differing in their resistance to race 1 of the pathogen. Plantlets were transplanted into unamended soil naturally infested with the pathogen, soil amended with urea and soil amended with aged chicken manure. A corm invasion score was also developed to assess the accuracy of the foliar symptom score as an indicator of cultivar resistance. On the basis of foliar symptom scores alone, the response of five of the seven cultivars in the chicken manure treatment corresponded to their known field response. However, the response of the other two cultivars, both susceptible to the pathogen in the field, fell into two categories. One had a high foliar symptom score and a correspondingly high corm invasion score, whereas the other had a low foliar symptom score and a high corm invasion score. Breeders need to be aware of the two categories of susceptible response, if inferior breeding material is to be rejected early on in a breeding program.
\end{abstract}

Additional keywords: Panama disease, nitrogen, resistance evaluation.

\section{Introduction}

The use of resistant plant breeding material has been the only successful long-term strategy in managing Fusarium wilt of bananas (Panama disease) caused by Fusarium oxysporum f. sp. cubense (Foc). Screening germplasm for improved cultivars has been restricted to field trials of adult plant material, due to the lack of a reproducible laboratory assay. In some laboratory studies, the response of juvenile planting material did not reflect adult plant resistance (Waite 1977), and in others, clones screened as resistant in the laboratory failed to perform in the field (Hwang and Ko 1987). The results of other laboratory assays have been questioned due to the use of unrealistically high inoculum levels to challenge plantlets (Pegg and Langdon 1987; Buddenhagen 1990). Recently, Pittaway et al. (1999) established that amending field soil naturally infested with Foc with chicken manure increased the severity of Panama disease. The increase in disease severity relative to the unamended control could be reproduced in susceptible plantlets grown in soils naturally infested with either race 1 or race 4 of the pathogen. Depending on the rate of chicken manure applied and on the age of the banana plantlet at transplanting, differences in the response of field-resistant and field-susceptible cultivars could be reproduced.

In the banana plant, the leaf trace vascular bundles are aggregated within the tissue located at the base of the pseudostem. Although rhizomatous in origin, this tissue is commonly referred to as a corm to designate its location and limited capacity for horizontal growth (Simmonds 1960). Leaf differentiation occurs vertically from the growing point, with leaf traces inserted in a circular pattern in the corm (Stover and Simmonds 1972). Within the roots the vascular system is more dispersed, with adjacent tracheids not necessarily derived from the same leaf. Therefore, occlusion of one or two vessels in the root may be reflected in the localised yellowing of one or more leaves. Establishing a consistent association between foliar symptoms and disease progression in the corm is a prerequisite in the development of a non-destructive score for evaluating the resistance of cultivars to disease. 
Infection of banana roots by Foc may occur at any growth stage. With the exception of sucker rhizomes being infected directly from diseased mother plants, all infection sites originate in the roots (Brandes 1919; Wardlaw 1941). Within 2 days of infecting a lateral root, hyphae can invade the vessels of the vascular system (Sequeira et al. 1958). The plant responds to invasion by secreting gels and forming tyloses. Both resistant and susceptible cultivars of banana are infected by Foc. In a resistant cultivar, complete occlusion of the vessels close to the invading hyphae can occur within 4 days of infection (Beckman and Halmos 1962). However, adverse environmental conditions have resulted in the breakdown of resistance in Cavendish to race 1 in the field (Beckman et al. 1962; Stover and Malo 1972). In susceptible cultivars, the delay in the formation of tyloses and the early breakdown of gels by the pathogen facilitates the spread of microconidia and hyphae through the vessels (Beckman et al. 1962, MacHardy and Beckman 1981). A delay in the formation of tyloses was also attributed to the breakdown of resistance in Cavendish to a strain of the pathogen to which it was normally field resistant. Symptom expression in the foliage can be very rapid, progressing from a faint, pale-yellow streak at the base of the petiole of the oldest leaf to total wilting of the leaf within several days. There may or may not be a longitudinal splitting at the base of the pseudostem. Splitting most commonly occurs in young, rapidly growing plants (Brandes 1919; Simmonds 1960; Stover 1962). In this study, the severity of disease in a range of banana cultivars varying in their susceptibility to race 1 of the pathogen was evaluated after adding aged chicken manure and urea to a soil naturally infested with the pathogen. The progress of foliar symptoms was compared with the progress of corm invasion, to validate the accuracy of the foliar symptom score in predicting the known field response of cultivars to Panama disease.

\section{Methods}

\section{Soil preparation}

Field soil was collected to a depth of $20 \mathrm{~cm}$ from under the canopy of mature plants of banana cv. Lady Finger growing on two commercial properties near Currumbin $\left(28^{\circ} 15^{\prime} \mathrm{S}, 153^{\circ} 26^{\prime} \mathrm{E}\right)$ in south-east Queensland, Australia. The two properties were known to be infested with race 1 of the pathogen, with only one Vegetative Compatibility Group having been detected (VCG 0125, Pittaway et al. 1999). Before use, the soil was coarsely sieved $\left(1 \mathrm{~cm}^{2}\right.$ grid) to remove plant debris and to break larger soil aggregates. Experimental treatments consisted of amending the soil at a ratio of 9:1 (v:v) field soil with aged chicken manure, or with $500 \mathrm{mg} / \mathrm{kg}$ of urea (equivalent to the available nitrogen level of the chicken manure-amended treatment (Pittaway et al. 1999). The chicken manure was taken at a depth of $60 \mathrm{~cm}$ from accumulated litter in a layer hen shed (manure had accumulated over 6 months). The urea was added to the soil 3 days prior to transplanting the banana plantlets. The control treatment was unamended soil.

The soil mixes were placed into ten trays per treatment, each tray $44 \times 70 \mathrm{~cm}$ and $26 \mathrm{~cm}$ deep. Soil was placed on geofabric (Bidim A12 Geofabrics Australia), over a 2-3 cm deep bed of washed sand in each tray and capillary watered by refilling two wine bottles inverted with their necks in the sand to maintain a permanent reservoir. Sterile gravel was placed over the surface of each tray to improve capillary rise of water to the surface. The 30 trays were interspersed on two benches in a glasshouse during March 1996, when recorded maximum and minimum temperatures were 40 and $25^{\circ} \mathrm{C}$, respectively. All soil treatments were equilibrated under capillary watering for 14 days before the plantlets were transplanted into the soil mixes. Weeds germinating during this time were removed by hand.

\section{Banana plantlet preparation and the foliar symptom score}

Based on their known field resistance to race 1 (Pegg, unpublished data), four susceptible cultivars and three resistant cultivars were deflasked from tissue culture at 6 weeks of age, and grown on for a further 8 weeks in a soil-less potting medium before transplanting. The potting mix consisted of equal quantities of perlite, peat and vermiculite amended with $2 \mathrm{~g} / \mathrm{L}$ Mini Osmocote (Scotts International, Heerlen, Netherlands) slow-release fertiliser. The susceptible cultivars were Gros Michel (AAA, highly susceptible), Sugar (Silk, AAB, highly susceptible), Pisang Ceylan (AAB, susceptible) and Lady Finger (Pome, AAB, susceptible). The resistant cultivars were Williams (AAA, highly resistant), Bluggoe (ABB, highly resistant) and Goldfinger (AAAB, highly resistant). At transplanting, one plantlet of each of the seven cultivars was transplanted into each of the ten trays per treatment (ten plantlets per cultivar per treatment; total 70 plantlets per treatment). Damage to the roots at transplanting was minimised by the use of capillary watering of the soil, reducing the potential for compaction during and after the 14-day equilibration period.

The progress of foliar disease symptoms for each cultivar in each treatment was described on a weekly basis. The progress of foliar symptom development was divided into five discrete categories. The categories were defined according to the extent of individual leaf yellowing and leaf wilting, and according to the proportion of the leaves of each plantlet affected (Table 1). The plantlets were harvested after 4 weeks.

\section{Corm invasion score}

The frequency of invasion of the pseudostem of each plantlet by Foc was calculated using the method of Pittaway et al. (1999) with the following modification. After surface sterilisation, the pseudostem/corm tissue was divided into three horizontal regions. Each region was numbered sequentially from the base of the plant and then each region was cut into ten pieces and plated onto 1/6 strength potato-dextrose agar amended with $0.5 \mathrm{~g} / \mathrm{L}$ streptomycin. Isolates putatively identified as $F O C$ on the basis of colony morphology and pigmentation (Booth 1971) were tested against the Race 1 tester strains VCG 0125 and 0124 (Correll et al. 1987). The identification was confirmed if one pure culture recovered from each pseudostem/corm was capable of forming an effective heterokaryon. Invasion of the pseudostem/corm by Foc was ranked into six categories according to the extent of invasion within each of the three regions of tissue (corm invasion score, Table 1).

\section{Analysis of the data}

The first objective of the experiment was to determine whether an equivalent application of urea to naturally infested soil could reproduce the same effect as the addition of chicken manure. The results for all seven cultivars were pooled to compare the frequency of plantlets showing foliar disease symptoms with the frequency of plantlets from which Foc was recovered from the pseudostem/corm tissue. The results for the urea and chicken manure treatments were compared with the results for the unamended soil.

The reliability of the foliar symptom score was assessed by comparing the score recorded for plantlets in the chicken manure-amended treatment with the corm invasion score. The foliar 
Table 1. Scoring systems for foliar symptoms and corm invasion used to describe the severity of Panama disease symptoms in individual banana plantlets

\begin{tabular}{|c|c|c|c|c|}
\hline \multirow[t]{2}{*}{ Score } & \multicolumn{2}{|c|}{ Foliar symptoms } & \multicolumn{2}{|r|}{ Corm invasion } \\
\hline & Individual leaf symptom & $\begin{array}{c}\text { Proportion of leaves } \\
\text { affected }(\%)\end{array}$ & Score & $\begin{array}{l}\% F o c \text { recovery in the } \\
\text { sequence CS-1, CS-2, Ps }\end{array}$ \\
\hline 0 & 0 & 0 & 0 & $0,0,0$ \\
\hline 1 & Yellowing & $<50$ & 1 & $50,0,0$ \\
\hline 2 & Yellowing or & $\begin{array}{l}>50 \\
<50\end{array}$ & 2 & $>50,0,0$ or \\
\hline 3 & $\begin{array}{l}\text { Yellowing and tip wilting } \\
\text { and } \\
\text { Total leaf wilting }\end{array}$ & $\begin{array}{l}>50 \\
<50\end{array}$ & 3 & $>50,<50,0$ \\
\hline 4 & $\begin{array}{l}\text { Yellowing and tip wilting } \\
\text { and Total leaf wilting }\end{array}$ & $\begin{array}{l}>50 \\
>50\end{array}$ & 4 & $>50,>50,0$ \\
\hline 5 & Stem base split & & $\begin{array}{l}5 \\
6\end{array}$ & $\begin{array}{c}>50,>50,<50 \\
>50,>50,>50\end{array}$ \\
\hline
\end{tabular}

${ }^{\mathrm{A}}$ Corm and pseudostem tissue was divided horizontally from the base into three sequential regions, corm section 1 (CS-1), corm section 2 (CS-2) and pseudostem (Ps). The percentage Fusarium oxysporum f. sp. cubense (Foc) recovery is the frequency of recovery of $F o c$ from the ten subsections cut from each of the three regions in sequence.

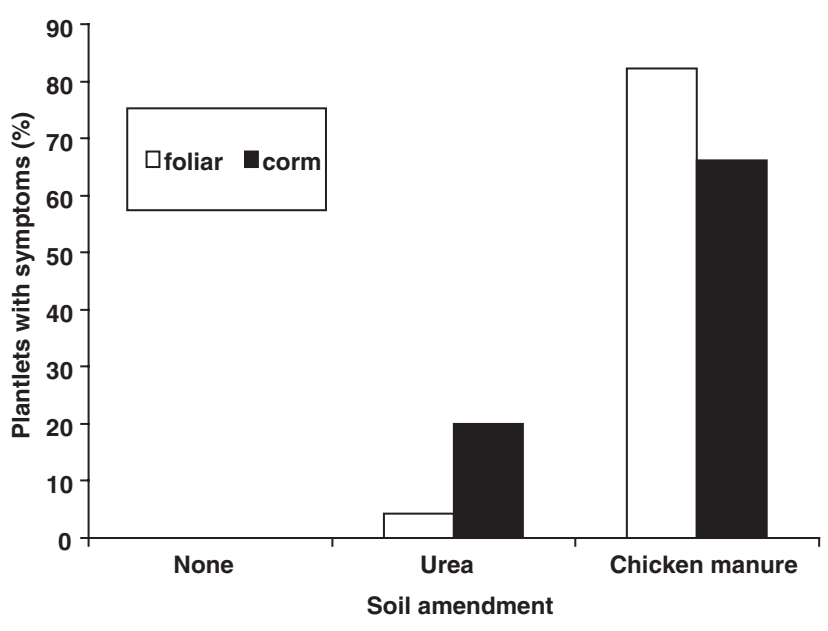

Fig. 1. Percentage of banana plantlets at 4 weeks after transplanting that showed foliar symptoms of Panama disease (open bars) and from which Fusarium oxysporum f. sp. cubense race 1 (VCG 0125) was recovered from the corm/pseudostem (solid bars). Results for all seven cultivars were pooled (total 70 plantlets per treatment). Treatments were soil naturally infested with Foc amended with $10 \%$ v:v aged chicken manure, or urea $(500 \mathrm{mg} / \mathrm{kg})$. The control was unamended, naturally infested soil.

symptom score recorded at the end of the fourth week was used. The results for all cultivars were pooled (total 70 plantlets) and presented as the frequency of the total plantlet population falling into each of the five foliar disease categories. Similarly, the proportion of the total plantlet population falling into each of the six corm invasion categories was also calculated.

Once the reliability of the foliar disease index was established, the scores recorded weekly over the 4-week duration of the assay were analysed for the chicken manure-amended treatment only. Results for each cultivar were analysed using an ordinal logistic regression model (McCullagh 1980) and the SAS LOGISTIC procedure (version 6.12). Cultivar responses were compared by deriving pair-wise log odds ratios and their standard errors. The statistical significance of the parameter estimates was assessed by using a Wald chi square test. The results of the pairwise comparisons were used to group the cultivars according to the severity of foliar symptom development. The response of the cultivars was ranked against the industry standard for banana production in soils infested with race 1 (cv. Williams, Pegg et al. 1996).

\section{Results}

\section{Effect of urea on the severity of Panama disease}

Unexpectedly, there were no symptoms of disease observed and no isolates of $F O C$ recovered from plantlets in the naturally infested, unamended control (Fig. 1). In the soil amended with urea, $4.3 \%$ of the banana plantlets showed foliar symptoms and Foc was isolated from the pseudostem/corm tissue of $20 \%$ of the plantlets. Urea is a readily available source of nitrogen for plant growth and visually, the addition of urea enhanced the growth of banana plantlets. Leaf initiation was faster and leaves were a deeper green with a larger surface area. A growth stimulation was also observed in the soil amended with chicken manure relative to controls.

However, amending the soil with urea did not reproduce the severity of Panama disease observed in the soil amended with chicken manure (Fig. 1). Foliar symptoms of the disease were evident in $82.3 \%$ of plantlets in the chicken manure treatment, with Foc recovered from the pseudostem/corm tissue of $66.2 \%$ of the plantlets.

\section{Foliar symptom score as an index of plantlet susceptibility to Panama disease}

In the chicken manure treatment, the first foliar disease symptoms occurred between 7 and 10 days after transplanting. Initially small $(<1 \mathrm{~mm}$ in diameter) discrete, circular patches of yellow tissue were observed on the leaves of affected plants. Over time, the yellowing extended along 


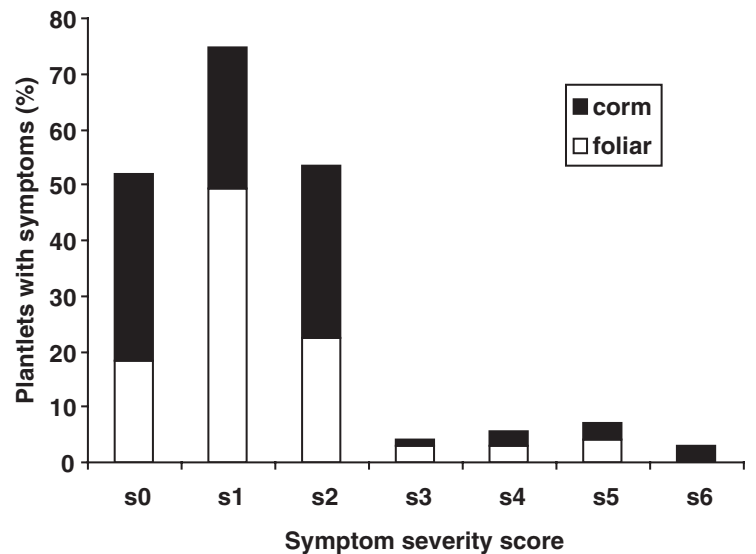

Fig. 2. Percentage of banana plantlets allocated to one of the five categories of foliar symptom scores (open bars), or one of the six categories of corm invasion scores (solid bars) in the chicken manure-amended treatment. Results for all cultivars were pooled (total 70 plantlets).

the major veins, producing a streak extending to the tip of the leaf. Wilting commenced at the tip of the leaf and progressed along the leaf blade until the whole leaf collapsed. The final stage in the temporal progression of disease symptoms was the longitudinal splitting of the pseudostem at the base of the plantlet. For most cultivars, the progression of foliar symptoms over time followed a consistent sequence. None of the cultivars had developed any foliar symptoms within the first week. By week 2, all cultivars had a similar proportion of plantlets showing category 1 foliar symptoms. By week 3 , major differences in foliar disease were evident between the cultivars. For example, the highly field-resistant cv. Bluggoe plantlets had not progressed beyond a score of 1 , and only $10 \%$ of the resistant Goldfinger plantlets had progressed to a score of 2, whereas $60 \%$ of the susceptible Gros Michel plantlets were ranked as 2 or 3. By week 4, only the susceptible cultivars Gros Michel and Lady Finger had progressed beyond a score of 2, with two and one plantlet, respectively, showing stem-splitting symptoms.
In general, the foliar symptom score proved to be a reliable indicator of the extent of corm invasion in soil amended with chicken manure. As the severity of foliar symptoms increased, so too did the extent of corm invasion (Fig. 2). The majority of the cultivars rated with a foliar score of 1 or 2 had a corresponding corm invasion score of 1 or 2 . Disease symptom progression beyond a score of 2 was very rapid, with the most susceptible plantlets having a foliar disease rating of 3-5 and a corm rating of 3-6. Of the 70 plantlets grown in the chicken manure treatment, only six showed no foliar symptoms and had no evidence of pseudostem invasion. Unexpectedly, of these six plantlets, three were Sugar and three were Pisang Ceylan. On the basis of the performance of adult plants in the field, Sugar is considered to be highly susceptible and Pisang Ceylan susceptible to Foc race 1 (Pegg, unpublished data). Four of the ten Pisang Ceylan plantlets and only one of the Sugar plantlets progressed to a foliar symptom score of 2, consistent with their susceptibility status. Five Pisang Ceylan and six Sugar plantlets had no foliar symptoms, yet corm invasion was relatively extensive (scores of 1 or 2 ). Hence for these two cultivars, the relationship between corm invasion and foliar symptoms was not consistent.

\section{Progression of foliar symptoms over time}

Ordinal logistic regression analysis of the change in foliar symptom scores over time, showed significantly different responses in the seven cultivars (Table 2). Over the 4-week duration of the assay, the foliar symptom scores for the resistant cultivars did not progress beyond 1 . In contrast, for susceptible cultivars, progression to scores of 2 to 3 or 4 within 1 week was common. With the exception of Sugar and Pisang Ceylan, the known field resistance of the cultivars was reflected in the pairwise comparisons. The response of the highly susceptible Gros Michel was no different from Lady Finger, and the resistant Williams and Goldfinger responses were essentially identical, with no significant difference between these cultivars and Bluggoe (highly resistant).

Table 2. Disease resistance ranking scores ( 1 most resistant, 7 least resistant) for the seven cultivars derived from the foliar symptom scores and from known field performance in soils infested with Fusarium oxysporum $\mathrm{f}$. sp. cubense race 1 (VCG 0125)

\begin{tabular}{lccc}
\hline Cultivar & Foliar symptom ranking & Log of the odds ratio & Field test ranking $^{\mathrm{B}}$ \\
\hline Sugar & 1 & $2.73 \mathrm{a}^{\mathrm{C}}$ & 6.5 \\
Pisang Ceylan & 2 & $1.06 \mathrm{ab}$ & 4.5 \\
Bluggoe & 3 & $0.26 \mathrm{~b}$ & 1.5 \\
Goldfinger & 4.5 & $0.00 \mathrm{bc}$ & 3.0 \\
Williams & 4.5 & $0.00 \mathrm{bc}$ & 1.5 \\
Lady Finger & 6 & $-1.57 \mathrm{~cd}$ & 4.5 \\
Gros Michel & 7 & $-1.88 \mathrm{~d}$ & 6.5 \\
\hline
\end{tabular}

${ }^{\mathrm{A}} \log$ of the odds ratios for pairwise comparisons of cultivars relative to Williams were calculated from the foliar symptom score results.

${ }^{\mathrm{B}}$ Field ranking results (Pegg, unpublished data).

${ }^{\mathrm{C}}$ Estimated log of the odds ratio relative to cv. Williams. Estimates followed by the same letters are not significantly different $P=0.05$ using a pairwise Wald test. 
Currently cv. Williams is used as the preferred commercial banana cultivar in Australian plantations infested with Foc race 1. The ranking of Lady Finger, Gros Michel, Bluggoe and Goldfinger observed in this study (Table 2), reflect their known ranking relative to cv. Williams when grown in the field (Pegg, unpublished data). However, to be consistent with their known field rankings, the log of the odds ratios based on the foliar symptom scores for both Pisang Ceylan and Sugar should be negative (less than cv. Williams). The lack of consistency between the corm invasion score and the foliar symptom score for Pisang Ceylan and Sugar makes the relative performance of these cultivars meaningless.

\section{Discussion}

Nitrogen has been reported to influence the severity of Fusarium wilt diseases in numerous studies (Rishbeth 1957; Maurer and Baker 1965; Huber and Watson 1974). However, the results of this study suggest that the addition of available nitrogen alone cannot explain the effect of chicken manure in predisposing banana plantlets to Panama disease. Adding equivalent amounts of urea to infested soil to reproduce the observed increase in plant-available nitrogen did not reproduce the severity of Panama disease observed in soils amended with chicken manure (Fig. 1). In a more detailed study involving the application of different rates of urea, Butler was also unable to increase the severity of Panama disease in amended soils (Stover 1962). Amending soil-less media artificially inoculated with Foc with ammonium sulphate has been used for comparing the response of different banana cultivars to Panama disease (Sun and $\mathrm{Su}$ 1987). However, symptom expression was extreme and not representative of disease expression in the field. The foliar symptoms in the banana plantlets grown in the soil amended with urea in this study were consistent with those observed in the soil amended with chicken manure and were representative of disease expression in the field. The results of a related study (Nasir et al. 2003) implicate ammonium nitrogen and its effect on mineral nutrition and plant growth in predisposing banana plantlets to Panama disease.

In this study, all cultivars were invaded by Foc. The highly resistant cultivar Bluggoe developed limited foliar symptoms within the first fortnight (severity score of 1). No further increase in symptom severity was observed, except for one plantlet where a score of 2 was recorded. Correspondingly, invasion of the corm and pseudostem after 4 weeks by Foc was also very restricted (corm invasion scores of 1 or 2). In theory, this reflects the vascular anatomy of banana plants, with limited invasion of tracheids in the roots expressed as discrete yellowing on only one or two leaves (foliar severity score of 1). Bluggoe was also the only cultivar to have a foliar score of 1 , in the absence of any Foc recoveries from the corm/pseudostem. This supports the notion that highly resistant cultivars rapidly mobilise an effective defence reaction against fungal infection, with little subsequent invasion developing (Beckman and Halmos 1962). More extensive invasion of the corm and pseudostem will lead to a greater proportion of the leaf traces being affected, resulting in progressively more severe leaf wilting. This type of reaction was observed in the cultivars Lady Finger and Gros Michel, known to be susceptible to Race 1 in the field. The field-resistant cultivars (Williams and Goldfinger) did not progress beyond a foliar symptom score of 2, with correspondingly restricted corm invasion.

In this study, the cultivars Pisang Ceylan and Sugar (both susceptible to Race 1 in the field) did not conform to this trend. In both cultivars, symptom expression was slow to develop, but the invasion of the corm and pseudostem by Foc was relatively extensive. In the most extreme case, after 4 weeks one Sugar plantlet recorded a foliar symptom score of 1 , but the corm invasion score was 4 . These observations suggest that the response to infection in these cultivars is very slow and ineffective, rendering them highly susceptible to Panama disease (Beckman et al. 1962). The early detection of such susceptible responses in breeding germplasm to invasion by Foc is extremely important in the development of cultivars with improved resistance. Scoring germplasm on the basis of foliar disease ratings alone (as in Table 2) may inadvertently lead to the inclusion of such material in advanced breeders' lines. Therefore, cultivars with low foliar symptom scores in laboratory assays must be checked for correspondingly low corm invasion scores to confirm their resistance rating.

This current study was restricted to assaying the response of banana cultivars to race 1 of the pathogen because, with the exception of cv. Goldfinger, very few cultivars with field resistance to race 4 (VCG 0120) are known. Knowledge of cultivar responses to tropical race 4 (VCG 01213/16) is even more limited, given that field-based studies have provided the only reproducible susceptibility rankings to date and germplasm field trials have only recently been established in the tropics (Nasir et al. 1999). An additional complication with field trials is that disease severity cannot easily be reproduced. The results of this study indicate that symptoms in banana plantlets reflecting adult plant resistance to Panama disease in the field can be reproduced in the laboratory using soils naturally infested with the pathogen. By varying the application rate of chicken manure and the age of the plantlets at transplanting, the severity of disease can be managed to expand the range of symptom expression in susceptible and resistant cultivars grown in different soil backgrounds naturally infested with different races of the pathogen. The non-destructive nature of the foliar symptom score developed in this study also enables the response of cultivars to be rated over the duration of the bioassay, allowing for differences in the rate of disease development to be assessed. However, destructive sampling is still required to verify that the foliar symptom score accurately reflects the 
extent of corm invasion, and to confirm the identity of the invading pathogen.

\section{Acknowledgements}

We gratefully acknowledge the cooperation of Dr Mike Smith and Ms Sharon Hamill in providing the tissue-cultured banana plantlets, and Dr Natalie Moore in providing the VCG tester strains for this study.

\section{References}

Beckman CH, Halmos S (1962) Relation of vascular occluding reactions in banana root to pathogenicity of root invading fungi. Phytopathology 52, 893-897.

Beckman CH, Halmos S, Mace M (1962) The interaction of host, pathogen and soil temperature in relation to susceptibility to fusarium wilt of bananas. Phytopathology 52, 134-140.

Booth C (1971) 'The genus Fusarium.' (Commonwealth Mycological Institute: England)

Brandes EW (1919) Banana wilt. Phytopathology 9, 339-383.

Buddenhagen IW (1990) Banana breeding and Fusarium wilt. In 'Fusarium wilt of banana'. (Ed. RC Ploetz) pp. 107-114. (American Phytopathological Society Press: St Paul, Minnessota)

Correll JC, Klittich CJR, Leslie JF (1987) Nitrate non-utilising mutants of Fusarium oxysporum and their use in vegetative compatibility tests. Phytopathology 77, 1640-1646.

Huber DM, Watson RD (1974) Nitrogen form and plant disease. Annual Review of Phytopathology 12, 139-165.

Hwang SC, Ko WH (1987) Somaclonal variation of bananas and screening for resistance to Fusarium wilt. In 'Banana and plantain breeding strategies'. ACIAR Proceedings No. 21. (Eds GJ Persley, EA De Langhe) pp. 151-156. (ACIAR: Canberra)

MacHardy WE, Beckman CH (1981) Vascular wilt Fusaria. Infection and pathogenesis. In 'Fusarium diseases, biology and taxonomy'. (Eds PE Nelson, TA Toussoun, RJ Cook) pp. 365-390. (Pennsylvania State University Press: Pennsylvania)

McCullagh P (1980) Regression models for ordinal data. Journal of the Royal Statistics Society. 42, 109-142.

Maurer CL, Baker R (1965) Ecology of plant pathogens in soil: 1. Influence of glucose, cellulose and inorganic nitrogen amendments on the development of bean root rot. Phytopathology 55, 69-72.
Nasir N, Pittaway PA, Pegg KG (2003) Effect of organic amendments and solarisation on Fusarium wilt in susceptible banana plantlets, transplanted into naturally infested soil. Australian Journal of Agricultural Research 54, 251-257.

Nasir N, Pittaway PA, Pegg KG, Lisle AT (1999) A pilot study investigating the complexity of Fusarium wilt of bananas in West Sumatra, Indonesia. Australian Journal of Agricultural Research 50, 1279-1283.

Pegg KG, Langdon PW (1987) Fusarium wilt (Panama disease). A review. In 'Banana and plantain breeding strategies'. ACIAR Proceedings No. 21. (Eds GJ Persley, EA De Langhe) pp. 119-123. (ACIAR: Canberra)

Pegg KG, Moore NY, Bentley S (1996) Fusarium wilt of bananas. A review. Australian Journal of Agricultural Research 47, 637-650.

Pittaway PA, Nasir N, Pegg KG (1999) Soil receptivity and host-pathogen dynamics in soils naturally infested with Fusarium oxysporum f. sp. cubense, the cause of Panama disease in bananas. Australian Journal of Agricultural Research 50, 623-628.

Rishbeth J (1957) Fusarium wilt of bananas in Jamaica: 11. Some aspects of host-parasite relationships. Annals of Botany 21, 215-245.

Sequeira L, Steeves TA, Steeves MM, Riedhart JJ (1958) Role of root injury in Panama disease infections. Nature 182, 309-311.

Simmonds NW (1960) 'Bananas.' (Longmans: Bristol)

Stover RH (1962) 'Fusarial wilt (Panama disease) of bananas and other related Musa species.' (Commonwealth Mycological Institute: Kew, UK)

Stover RH, Malo SE (1972) The occurrence of fusarial wilt in normally resistant dwarf cavendish banana. Plant Disease Reporter 11, $1000-1003$.

Stover RH, Simmonds NW (1972) 'Bananas (3rd edn).' (Longmans: London)

Sun EJ, Su HJ (1987) Rapid method for determining differential pathogenicity of Fusarium oxysporum f. sp. cubense using banana plantlets. Tropical Agriculture (Trinidad) 61, 7-8.

Waite BH (1977) Inoculation studies and natural infection of banana varieties with races 1 and 2 of Fusarium oxysporum f. sp. cubense. Plant Disease Reporter 61, 15-19.

Wardlaw CW (1941) The banana in Central America. 111. Panama disease. Nature 147, 380-381.

Received 1 August 2002, accepted 16 June 2003 